\title{
Passenger Volume Prediction by a Combined Input-Output and Distributed Lag Model and Data Analytics of Industrial Investment
}

\author{
Fan Yang ${ }^{\mathbb{D}},{ }^{1}$ Zhao-guo Huang, ${ }^{2}$ Hua-zhi Yuan ${ }^{D},{ }^{2}$ Jian-jun Wang, ${ }^{1}$ Wei-jia Li, ${ }^{1}$ and \\ Sai Wang \\ ${ }^{1}$ School of Transportation Engineering, Chang'an University, Xi'an 710064, Shaanxi, China \\ ${ }^{2}$ School of Civil Engineering, Lanzhou University of Technology, Lanzhou 730050, Gansu, China \\ Correspondence should be addressed to Hua-zhi Yuan; 41810670@qq.com
}

Received 15 October 2020; Revised 2 November 2020; Accepted 12 November 2020; Published 29 November 2020

Academic Editor: Zhongxiang Feng

Copyright (c) 2020 Fan Yang et al. This is an open access article distributed under the Creative Commons Attribution License, which permits unrestricted use, distribution, and reproduction in any medium, provided the original work is properly cited.

\begin{abstract}
In order to sketch the transport infrastructure construction in an economy or a region, the government has to predict the passenger volume, under the local policy of industrial investment. In this paper, we propose a combined input-output and distributed lag prediction model of passenger volume in a province in P. R. China, under a certain policy of industrial investment called Silk Road Economic Belt. Specifically, the relationships between the passenger volume, GDP (gross domestic product), gross output, and transportation consumption are analyzed, and then the industrial development speed analysis and classification are used to calculate the average development speeds and the GDP contributions of 42 industries. Combining the input-output table, the provincial transportation consumption under the Silk Road Economic Belt policy is predicted, and the passenger volumes of the cities and the province in the future are predicted by the distributed lag models. Considering the uncertainty of the investment, the elastic ranges of the cities and the province's passenger volumes are determined. The results show that the correlation between the passenger volume and transportation consumption is the highest, and it is equal to 0.975 . In 2020, the passenger volume in Shaanxi is $1,641,305$ thousands, and the error between the predicted value and the value obtained by summing the cities' passenger volumes is smaller than $0.002 \%$.
\end{abstract}

\section{Introduction}

Before building the transport infrastructure in an economy or a region, the government has to predict the passenger volume under the local policy of industrial investment. The Silk Road Economic Belt is known as a strategic route that connects Asia, Europe, and Africa, which plays an important role in promoting the coordinated development of the economy and society in many regions in P. R. China. In order to better support the development of the Silk Road Economic Belt, the corresponding transport system should be established, which requires an accurate passenger volume prediction based on the data analytics under the local policy of industrial investment.

The traditional passenger volume prediction methods can be divided into qualitative, quantitative, and combined analysis methods. The qualitative passenger volume prediction methods include the Delphi method, expert meetings, brainstorming and personal judgment, and many others. The quantitative passenger volume prediction methods utilize the prediction theory and mathematical methods to sort, process, and simulate the raw data, which is further used to construct mathematical models needed to predict the passenger volume. Many models from the other fields like econometrics, physics, and mathematics, improved and combined prediction models, have much higher prediction accuracy than the traditional prediction models. The support vector machine was used to predict the passenger volume in a metropolitan area by gradually changing the parameter values of the loss function, penalty factor, and Gaussian kernel function [1]. The support vector regression (SVR) model was used to predict the subway passenger 
volume, and it was compared with the seasonal autoregressive integrated moving average (SARIMA) quadratic regression and linear regression [2]. The accuracy of the LSSVM-RBF neural network that combined radial basis function neural network and least squares support vector was much higher than the single model [3]. A time series passenger flow prediction method based on history and presale was used to predict the short-term and mediumterm railway passenger volumes; this model can control the total prediction error [4]. A chaos accelerated genetic algorithm was proposed, and an NCAGA-PPPG (accelerating genetic algorithm-parameter projection pursuit regression) mixed optimization passenger forecast model based on accelerated genetic algorithm improved by Gaussian distribution and elite local search was constructed [5]. Furthermore, the grey prediction method GM $(1,3)$ and Markov prediction method were used to forecast the highway passenger volume, and the obtained prediction result was more precise than that obtained by the grey prediction method [6]. The grey relational degree theory was used in the quantitative analysis of influencing factors of transport-channel passenger volume. A multifactor backpropagation (BP) neural network model was constructed and employed to predict the transport-corridor passenger volume [7]. The particle swarm algorithm optimization parameter that has good prediction performance and the grey method were combined in the greyvariation particles-group swarm prediction model that was proposed to forecast public passenger volume [8]. A logistic-based model was developed to predict the future passenger traffic in China in combination with the multivariate statistical analysis model by the factor analysis [9]. The cloud computing and parallel SVM model were employed to predict the railway passenger volume in China, and the results showed that the proposed combined prediction algorithm achieved good results $[10,11]$. The genetic algorithm (GA) and artificial neural network (ANN) were used to predict the monthly passenger volume of the railway in Serbia [12]. For more information about the passenger prediction by using some cutting-edge technologies, refer to references [13-18]. The machine learning method needs big data to predict the model. While for the passenger volume data, we only can collect several years data. It is not suitable to use the machine learning method to predict the passenger volume. Therefore, the combined input-output and distributed lag model and the system dynamics method will be used to do the prediction and compare the results.

The traditional passenger volume prediction methods do not consider the impact of the Silk Road Economic Belt policy on industrial investment development of transportation systems. With this policy, we focus on the economic and social exchanges between Shaanxi Province in P. R. China and other regions/nations, where the relevant industrial industries will bring different and new demands, and the transportation system will be influenced by other industrial industry. Hence, we conduct a case study using the data collected in Shaanxi Province, and we propose a prediction model for passenger volumes by combining the input-output tables, the distributed lag model of the traffic, and the economy, trade, and industry data. The results can provide accurate recommendations for infrastructure facilities planning and construction in the future.

\section{A Measurement Study of Transportation Consumption Based on Input-Output Table}

Although the GDP indicated the economy level, using only the development trend of the GDP to predict the passenger volume cannot reflect the influence of the industrial investment changes and industrial structure adjustment on the passenger volume. This influence can be determined by considering the gross output that can be obtained from the input-output table. However, the gross output does not consider direct and indirect dependency relationships between the transportation industry and the other industries, which affects the accuracy of prediction of passenger volume. In order to solve these problems, this paper introduces the concept of transportation consumption and analyzes the relationships between the GDP, gross output, transportation consumption, and passenger volume.

2.1. Analysis of Gross Input of Each Industry Based on InputOutput Table. The input-output model [19-22] based on the input-output table can be expressed as follows:

$$
\sum_{i=1}^{n} x_{i j}+N_{j}=X_{j} \cdot(j=1,2, \ldots n)
$$

The total direct consumption coefficient is expressed as $a_{c j}=\sum_{i=1}^{n} a_{i j}$, and $a_{c j} X_{j}+N_{j}=X_{j}$, so we have the following equation:

$$
A_{c} X+N=X,
$$

where $a_{c j}$ represents the total direct consumption coefficient of the jth column; thus, the material consumption of the $j$ th industry produces unit output value, known as direct material consumption coefficient.

Matrix $A_{c}$ is the diagonal matrix of the direct consumption coefficient of each column, and $\mathrm{Nj}$ denotes the GDP contribution of the $j$ th industry.

Based on the principle of the input-output model, the deformation can be expressed as follows:

$$
X=\left(1-A_{c}\right)^{-1} N .
$$

The crucial parameter in (3) is $N$, and this paper calculates the GDP value of 42 industries in the period 2007-2015 based on the input-output tables of years 2007 and 2012.

(1) Calculate the GDP contribution of each industry in 2007 and 2012 which are, respectively, denoted as $\triangle \mathrm{GDPP} 07$ and $\triangle \mathrm{GDPP} 12$ by 


$$
\begin{aligned}
\Delta \mathrm{GDPP}_{07} & =\frac{\Delta \mathrm{GDP}_{07}}{\mathrm{GDP}_{07}}, \\
\Delta \mathrm{GDPP}_{12} & =\frac{\Delta \mathrm{GDP}_{12}}{\mathrm{GDP}_{12}},
\end{aligned}
$$

where $\Delta \mathrm{GDP}_{07}$ and $\Delta \mathrm{GDP}_{12}$ represent the GDP of each industries in 2007 and 2012, respectively.

(2) Calculate $\triangle \mathrm{GDP}$ of each industries in the existing one year (such as 2014):

$\Delta \mathrm{GDP}_{i}=\mathrm{GDP}$ in existing one year $\times \Delta \mathrm{GDPP}_{07}$,

$\Delta \mathrm{GDP}_{j}=\mathrm{GDP}$ in existing one year $\times \Delta \mathrm{GDPP}_{12}$.

where $i$ ranges from 2008 to 2011 and $j$ ranges from 2013 to 2015.

The total provincial outputs in the period 2007-2015 are obtained by using the GDP of each industry and equation (3).

The investment of each industry induced by the Silk Road Economic Belt policy can contribute to the GDP improvement. And by using the relationship between the GDP and passenger volume, the passenger volume in the future is predicted.

2.2. Transportation Consumption Analysis. The transportation consumption can be calculated by the following equation:

$$
Q=\sum b_{j} X_{j},
$$

where $b_{j}$ represents the total transportation consumption coefficient of industries $j$ and $X_{j}$ represents the gross output of industries $j$.

The transportation consumption of Shaanxi Province in the period 2007-2015 can be calculated by (6), and the obtained results are given in Table 1.

2.3. Correlation Analysis. Each industry has different demands and transfer values of fixed asset requirements for transportation in the production process. Therefore, transportation consumption is in correlation with the traffic volume to a certain extent. In this work, the eight-year data corresponding to the period 2007-2015 and the Pearson correlation coefficient method are used to analyze the relationships between the passenger volume, GDP, gross output, and transportation consumption, and the obtained results are shown in Table 2. The reason that these three variables are used is lots of papers were verified and these three variables have a strong correlational relationship with passenger volume $[23,24]$.

As presented in Table 2, the correlation between the transportation consumption and passenger volume was higher than that of the other parameters, and thus constructing a combined passenger-volume transportationconsumption prediction model can be used to predict the passenger volume in Shaanxi Province.
TABLE 1: Transportation consumption in billions of yuans.

\begin{tabular}{lc}
\hline Year & Transportation consumption \\
\hline 2007 & 8323750 \\
2008 & 10921473 \\
2009 & 12198411 \\
2010 & 15115470 \\
2011 & 15500625 \\
2012 & 16118153 \\
2013 & 18071654 \\
2014 & 19727096 \\
2015 & 20264514 \\
\hline
\end{tabular}

TABLE 2: Pearson's correlation between variables.

\begin{tabular}{lccc}
\hline $\begin{array}{l}\text { Pearson } \\
\text { correlation }\end{array}$ & GDP & $\begin{array}{c}\text { Gross } \\
\text { output }\end{array}$ & $\begin{array}{c}\text { Transportation } \\
\text { consumption }\end{array}$ \\
\hline Passenger volume & $0.956^{* *}$ & $0.963^{* *}$ & $0.975^{* *}$ \\
& 0.000 & 0.000 & 0.000 \\
\hline
\end{tabular}

Note. ${ }^{* *}$ indicates 0.01 level is obvious.

\section{Provincial Passenger Volume Prediction Based on Consumption-Distributed Lag Models}

3.1. Design of Distributed Lag Models and Model Comparison. Almon proposed the polymerization lag model (PDL), and the equation of distributed lag models has exogenous variables:

$$
y_{t}=\alpha+\sum_{i=0}^{p} \beta_{i} x_{t-i}+u_{t}
$$

There exists multi-colinearity between explanatory variables, which cannot be estimated by the OLS, so $\beta_{i}$ is expressed as follows:

$$
\begin{aligned}
& \beta_{i}= \alpha_{0}+\alpha_{1}(i-\bar{p})+\alpha_{2}(i-\bar{p})^{2}+\cdots+\alpha_{q}(i-\bar{p})^{q}, \\
& q<p, i=0,1, \ldots, p, \\
& \bar{p}= \begin{cases}\frac{p}{2}, & p=2 k, \\
\frac{(p-1)}{2}, & p=2 k-1,\end{cases}
\end{aligned}
$$

This model considers the influence of independent variables before the current year, thus achieving relatively high prediction accuracy. In this work, regression and fitting of the passenger volume and transportation consumption in the period 2007-2015 are conducted; meanwhile, the EVIEWS software is used to construct distributed lag model between the passenger volume and transportation consumption, considering the precision requirements. In this study, the lag period and polynomial degree are both set to 3 . The fitting functions whose fitting degree is above 0.9 are given in Table 3. 
TABLE 3: Fitting functions.

\begin{tabular}{lcc}
\hline Model & Fitting function of passenger volume and transportation consumption & Fitting degree \\
\hline Linear & $y=7031.332-0.006 * x$ & 0.950 \\
Logarithm & $y=-1297720.709+84679.547 * \operatorname{In}(x)$ & 0.976 \\
Reciprocal & $y=176062.322-x / 1.077 * 10^{12}$ & 0.968 \\
Quadratic function & $y=-48172.326+0.014 * x-2.814 * 10^{-10} * x^{2}$ & 0.977 \\
Cubic function & $y=-48172.326+0.014 * x-2.814 * 10^{-10} * x^{2}$ & 0.977 \\
S type functions & $y=\mathrm{e}^{12.389-\left(-1.289 * 10^{7} / x\right)}$ & 0.981 \\
Distributed lag model & $y=65527.42-0.00163 * x_{t}+0.00225 * x_{t-1}+9.3 * 10^{-5} x_{t-2}+0.00299 * x_{t-3}$ & 0.996 \\
\hline
\end{tabular}

As presented in Table 3, the fitting degree of the distributed lag model is the highest, but the model' trends and adaptability should also be evaluated in the prediction of the passenger volume.

\subsection{Provincial Passenger Volume Prediction under Guidance} of Induced Industrial Investment. Following the Silk Road Economic Belt policy, the province projects, fast track of the investment, and construction programs yield to rapid economic development. Due to the industrial and regional advantages of Shaanxi Province, which represents the traffic origin of the Silk Road Economic Belt, the transportation of this province can achieve rapid development regarding both the quantity and the quality. The Shaanxi Province transportation increase is caused by the natural transportation increase and the value induced by industrial investment. So, the induced value should be considered in the passenger volume prediction of Shaanxi Province in the period 2016-2020, which can provide the theoretical basis for traffic planning in the future. The transportation consumption of Shaanxi Province in the period 2016-2020 can be predicted by the following steps.

(1) Estimate GDP $\mathrm{P}_{\text {the target year, }}$ which represents the added value of each industries in the target year, combining $\Delta \mathrm{GDP}_{2012}$ and the following equation:

$$
\mathrm{GDP}_{\text {the target year }}=\bar{R}^{p} \times \mathrm{GDP}_{\text {the current year }},
$$

where $p$ represents the number of years from the current year to the target future year.

According to the construction investment of 71 key projects launched in 2015, this paper predicts the GDP increase speed $\bar{R}$ under the Silk Road Economic Belt policy in Shaanxi Province. The mentioned 71 projects belong to 20 key construction industries and correspond to the total investment of 389 billion yuan. Based on this, 42 industries are divided into 22 general development industries and 20 key development industries. The calculation of the development speed of both groups of industry is given below.

(2) General industries' development speed calculation.

Take the input-output table in the base year 2012 (input-output tables are proposed every four year). Assume the GDP growth rates calculated at comparable prices in $n$ following years from 2012 are denoted as $R_{1}, R_{2}, \ldots, R_{n}$; then, the average development speed for the past few years is expressed as follows:

$$
\bar{R}=\sqrt[n]{R_{1} \times R_{2} \times \cdots \times R_{n}}
$$

The GDP growth rates for three consecutive years (2012-2015) calculated at comparable prices are $111.0 \%, 109.7 \%$, and $108.0 \%$. According to (10), the average development speed is expressed as $\bar{R}=\sqrt[3]{1.110 \times 1.097 \times 1.080}=109.56 \%$, which represents the general industries' development speed.

(3) Key industries' development speed calculation.

Under the influence of the Silk Road Economic Belt, Shaanxi Province will strive to develop the transport, trade and logistics, energy, science, education, and other industries so that the average development speeds of the key development industry are accelerated, and they are higher than those of the general development industry; thus, it is needed to recalculate the key industries' development speeds.

The increased investment in these industries has a strong multiplier effect on the economic development of the major and base projects and expands the domestic demand on traveling and causes the increase in the aggregate demand. The research shows that the increase in the investment rate of one percent will cause an increase of $0.095 \%$ in the economic development speed. Accordingly, the average development speed of key construction industry can be calculated by the following equation:

$$
\bar{R}_{x}=\bar{R}+\frac{I-I_{0}}{1 \%} \times 0.095 \%,
$$

where $I_{0}$ represents the background investment rate of various industries in 2015 and I represents the total investment rate of various industries in 2015 .

The prediction results of key industries' average development speed in the period from 2015 to 2020 are shown in Figure 1.

This article predicts the GDP of 42 industries from 2016 to 2020 based on the input-output tables of 42 industries in 2012. That is, $\bar{R}$ and $\bar{R}_{x}$ are combined to predict the increase in GDP of all 42 industries, but this paper presents only a part of the prediction results. Summing the prediction results of all of the industries, the provincial GDP prediction under the 


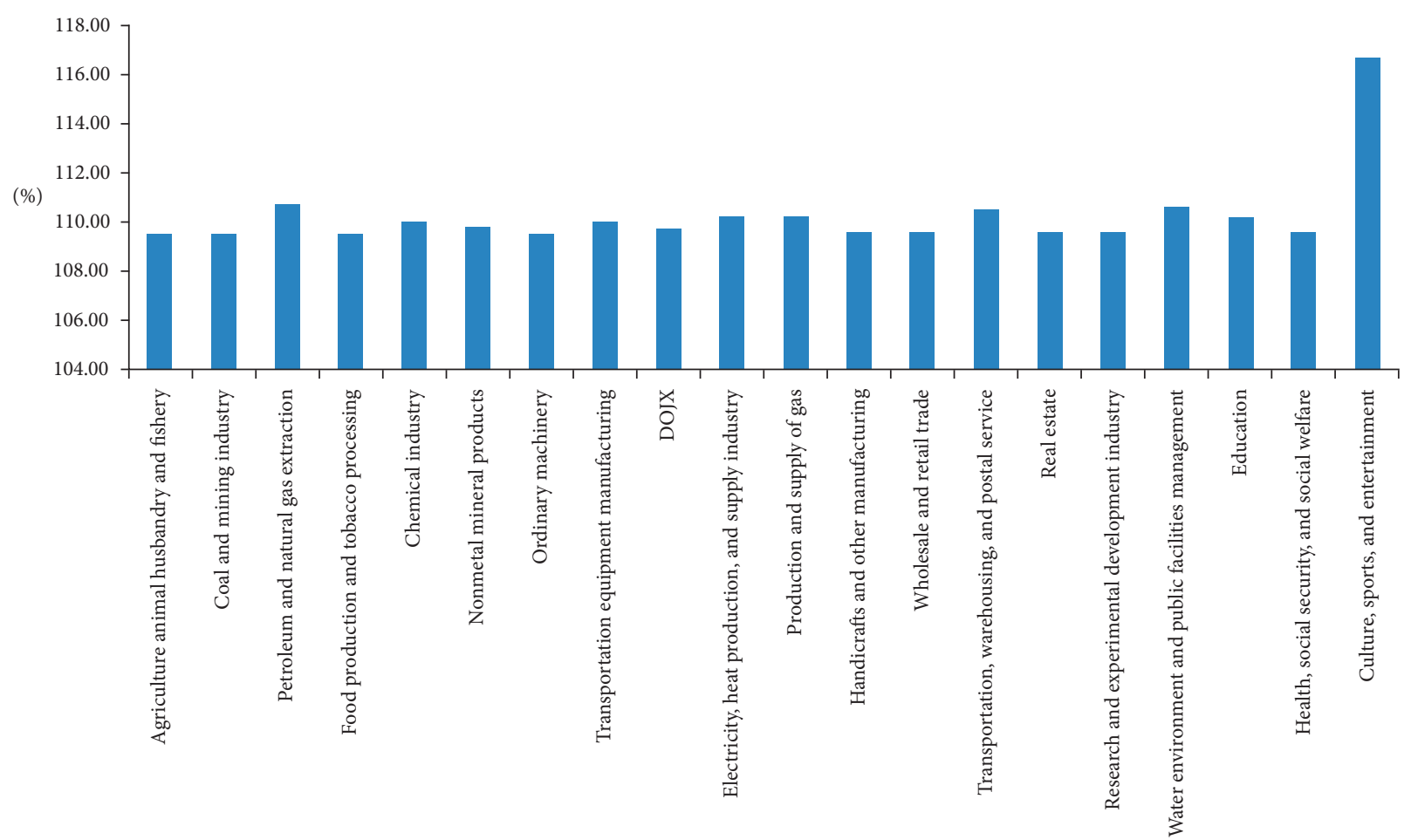

Figure 1: Prediction results of the average development speed of the key development industry from 2015 to 2020.

background of the Silk Road Economic Belt policy and the difference in the industrial development speed can be obtained.

(4) Transportation consumption prediction.

According to the provincial GDP prediction in the period 2016-2020 that considers the influence of induced industrials, by using (3), the gross output of each industry can be obtained, and the results are shown in Table 4. Also, (9) can be used to predict the transportation consumption of Shaanxi Province in the period 2016-2020, and the predicted values are shown in Table 5.

(5) Passenger volume prediction.

The distributed lag model is used to predict the passenger volume of Shaanxi Province in the period 2016-2020, and the results are shown in Table 6 .

In order to test the model prediction accuracy, another method named system dynamics was also used to predict the passenger volume that considers the stimulation of the Silk Road Economic Belt.

The state variables in this system include Shaanxi province fee level (yuan), Shaanxi province CPI consumer price index, Shaanxi province national (yuan), Shaanxi province highway mileage (ten thousand kilometers), Shaanxi province railway operating mileage (ten thousand kilometers), Shaanxi province traffic fixed asset investment in transportation, warehousing, and postal industry (100 million yuan), highway passenger traffic in
Shaanxi Province, and railway passenger traffic in Shaanxi Province. Speed variables include the growth rate of residents' consumption level, GDP growth rate, highway mileage growth rate, railway operating mileage growth rate, highway passenger traffic growth rate, and railway passenger traffic growth rate [25-27]. The auxiliary variable is mainly time, that is, the study period of this article, from 2007 to 2020.

The consumption level of residents changes with the year. Therefore, the consumption level of residents is an implicit function of the year. CPI is affected by time and residents' consumption level; therefore, an implicit function of CPI on residents' consumption level can be established. GDP changes with changes in CPI; therefore, an implicit function of GDP to CPI is established. The fixed asset investment in transportation, storage, and postal industry changes with GDP, and the implicit function of fixed asset investment in transportation, storage, and postal industry on GDP is established. Highway mileage is affected by fixed asset investment in transportation and warehousing and postal industry. Therefore, an implicit function of road mileage on fixed asset investment in transportation and warehousing and postal industry can be established.

Highway passenger traffic is affected by the consumption level of residents, CPI, GDP, fixed asset investment in transportation, storage, and postal industry, and highway mileage. Railway passenger 
TABLE 4: The province GDP (gross domestic product) and gross output prediction in tens of thousands of yuans.

\begin{tabular}{|c|c|c|c|c|c|}
\hline Industry number & GDP12 & GDPP12 & GDP15 & GDP16 & OUT16 \\
\hline 1 & 13701600 & 0.0948 & 17226923.28 & 18878985.22 & 31735080 \\
\hline 2 & 14980668 & 0.1036 & 18826046.96 & 20627699.65 & 36652022 \\
\hline 3 & 12851019 & 0.0889 & 16154783.54 & 17894653.73 & 25061437 \\
\hline 4 & 1329204 & 0.0092 & 1671811.12 & 1831636.263 & 4938746 \\
\hline$\vdots$ & $\vdots$ & $\vdots$ & $\vdots$ & $\vdots$ & $\vdots$ \\
\hline 40 & 2014447 & 0.0139 & 2525888.54 & 2769889.373 & 6082917 \\
\hline 41 & 758947 & 0.0053 & 963108.58 & 1124332.956 & 2602750 \\
\hline 42 & 5160940 & 0.0357 & 6487354.02 & 7107545.064 & 11849397 \\
\hline
\end{tabular}

TABLE 5: Prediction results of province transportation consumption in billions of yuans.

\begin{tabular}{lccccc}
\hline Year & 2016 & 2017 & 2018 & 2019 & 2020 \\
\hline Transportation consumption & 24609740 & 27042887 & 29717088 & 32656276 & 35886768 \\
\hline
\end{tabular}

TABLE 6: Predicted passenger volume in thousands of people.

\begin{tabular}{lccccc}
\hline Year & 2016 & 2017 & 2018 & 2019 & 2020 \\
\hline $\begin{array}{l}\text { Passenger } \\
\text { volume }\end{array}$ & 126877.6 & 137688 & 140814.7 & 155259.2 & 164130.5 \\
\hline
\end{tabular}

traffic is affected by the consumption level of residents, CPI, GDP, fixed asset investment in transportation, storage, and postal industry, and railway mileage. The growth rate of highway passenger traffic is affected by the growth rate of residents' consumption level, CPI, GDP growth rate, fixed asset investment growth rate of transportation, storage, and postal industry, and the growth rate of highway mileage. The growth rate of railway passenger traffic is affected by the growth rate of residents' consumption level, CPI, GDP growth rate, transportation, storage, and postal industry's fixed asset investment growth rate, and railway operating mileage growth rate. Establish a regression model and analyze its algebraic relationship with influencing factors.

Road passenger traffic volume in the $i$ year $=$ $(1+$ highway passenger traffic growth rate in the $i$ year) $\times$ road passenger traffic volume in the $i$ year

The flow diagram of the entire system is shown in Figure 2.

Input the relationship between the variables in the model to Vensim for simulation.

Compared with $\mathrm{R} 2$, the prediction accuracy of a combined input-output and distributed lag model proposed in this study is higher.

\section{Passenger Volume Sensitivity and Scale Analysis under Influence of Industrial Investment}

The fluctuation in the passenger volume of the cities can cause a prediction error because the development speeds that are based on the investment are uncertain, and the impact of that error (there can be construction information that cannot be collected) can be determined by the quantitative analysis. Considering that Shaanxi Province will strongly develop industries to adapt to the development of the domestic and international Silk Road Economic Belt construction and the development of the third industry will strongly increase the passenger volume, this paper focuses on the investment sensitivity of the third industry. The test number is $C_{12}^{1}+C_{12}^{2} \cdots+C_{12}^{12}$ which will strongly increase the testing work, which is very difficult to implement, so the investment sensitivity of each industry is analyzed first. The influence of the $1 \%$ increase in the industrial investment of each industry on the passenger volume is shown in Figure 2 and in Table 7.

As shown in Figure 3, the third industry has a positive effect on the passenger volume, but there exist differences in the effects of industries; the influence value of the financial industry on the passenger volume is the highest, and $1 \%$ increase in this will increase the passenger volume by 161.46 tens of thousands of people. The financial industry is followed by leasing and commercial service, accommodation and restaurants, real estate, information transmission, software and information technology services, and others.

The combined analysis of the industrial development speeds is as follows: assume that the development speed of accommodation and restaurants increases by $1 \%$ along with the information transmission and software and information technology services. Then, the passenger volume in 2020 will be 164159.85 tens of thousands of people; thus, it will differ by 29.34 tens of thousands of people from the passenger volume predicted in Section 3.2. In Figure 2, it can be seen that when the development speeds of accommodation and restaurants, information transmission, and software and information technology services increase by $1 \%$, the increase of passenger volume will be 29.38 , so the prediction error is $0.1 \%$. The error of the other industries' combination can be obtained using the results presented in Figure 2.

Considering that the third industry has a positive effect on the passenger volume, the maximum passenger volume can be obtained using the maximum development speed of the third industry. The maximum development speed from 2012 to 2015 is $\bar{R}=111.0 \%$, which is $1.3 \%$ larger than 


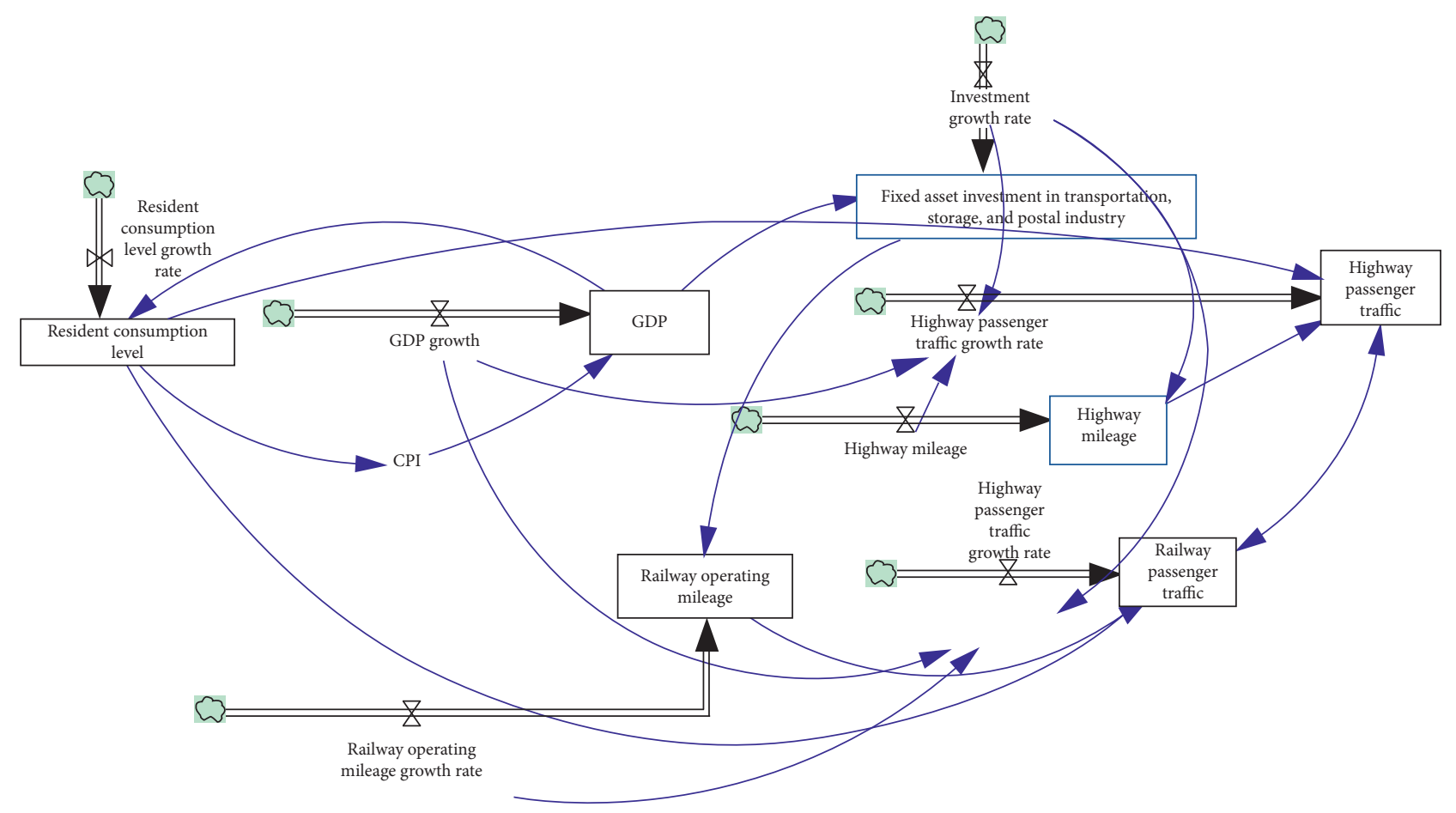

Figure 2: Causal relationship diagram and system flow diagram.

TABLE 7: Simulation results of highway passenger traffic and railway passenger traffic based on growth rate.

\begin{tabular}{lccccc}
\hline Year & 2016 & 2017 & 2018 & 2019 & 2020 \\
\hline Passenger volume & 136660 & 139345 & 134953 & 133562 & 139972 \\
\hline
\end{tabular}

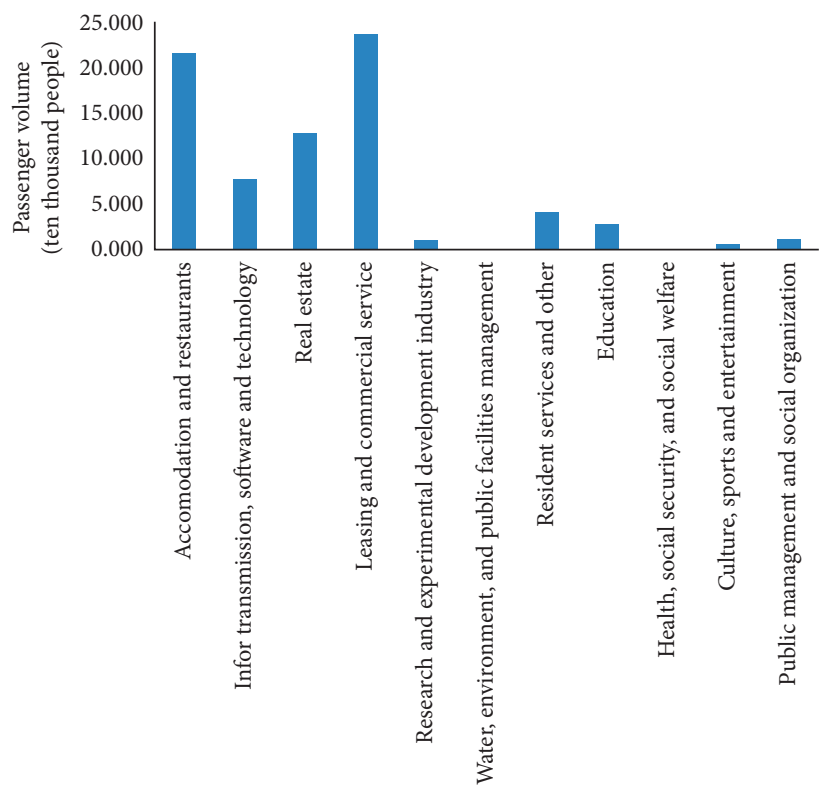

FIGURE 3: Sensitivity of the province passenger volume.

$\bar{R}=109.56 \%$. Thus, when the development speed of the third industry increases by $n$ percent, the passenger volume will be

$$
\mathrm{KY}=140504.812+23625.975 *(1+n) .
$$

For instance, at $n$ of $1.3 \%$, the elastic range of the passenger volume is $[164130.5,164437.9]$ in tens of thousands of people. 

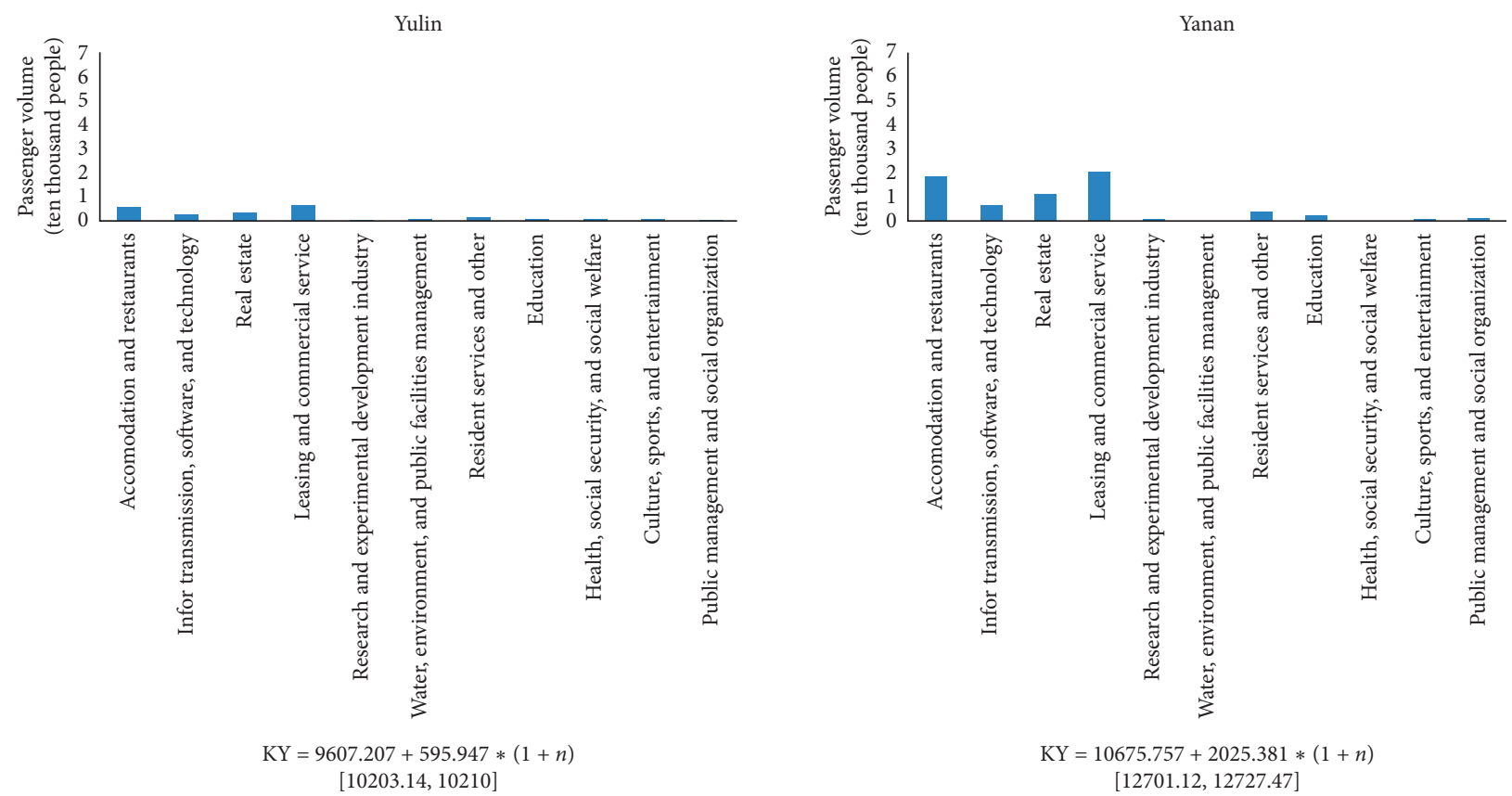

(a)

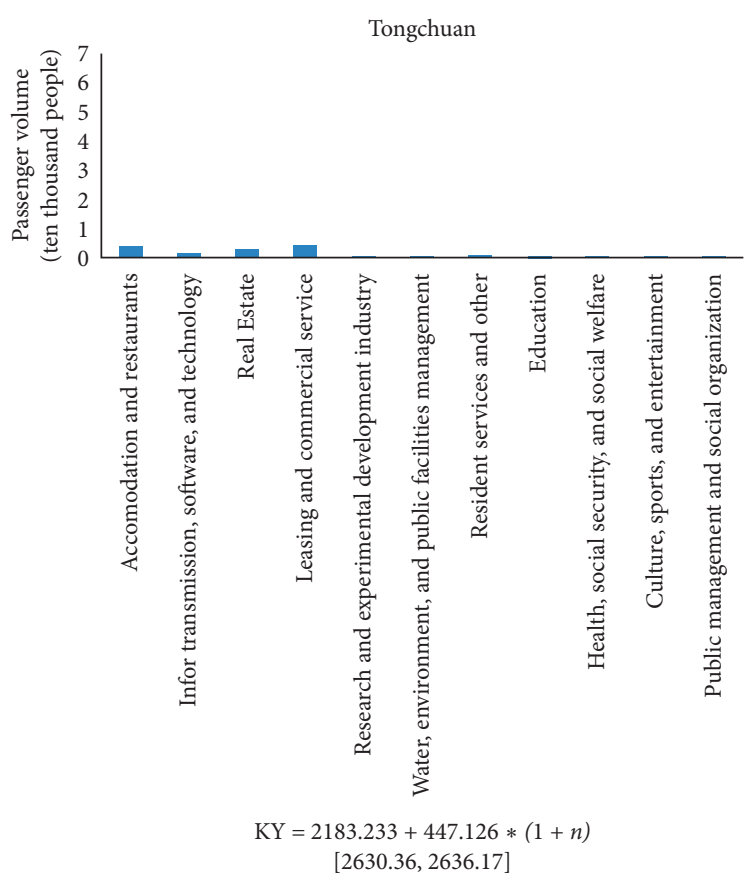

(d)

Figure 4: Continued. 


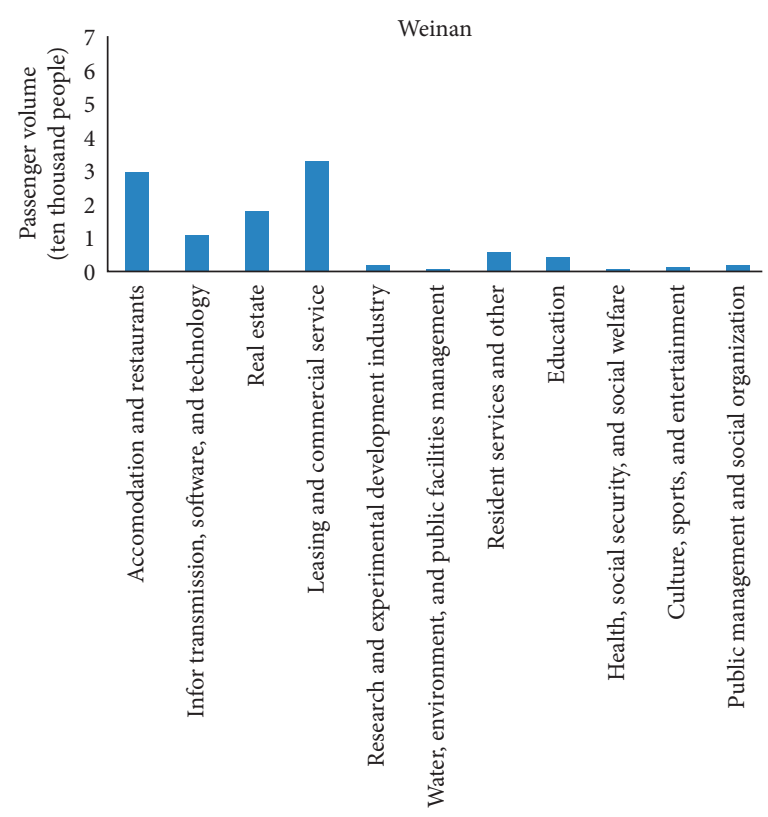

$\mathrm{KY}=17019.069+3260.211 *(1+n)$

[20279.25, 20321.66]

(e)

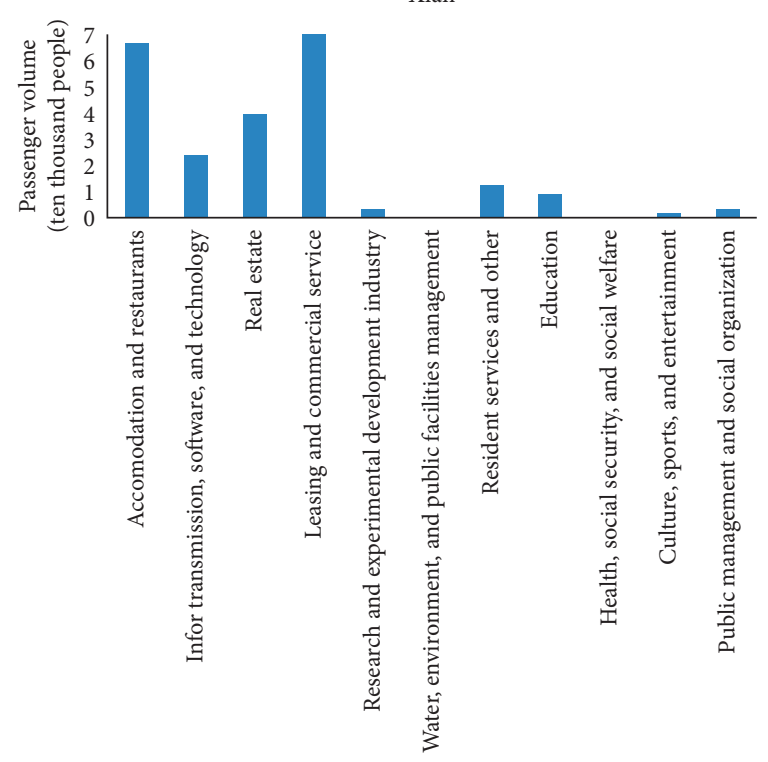

$\mathrm{KY}=42379.097+7306.771 *(1+n)$

[49685.78, 49780.86]

(g)

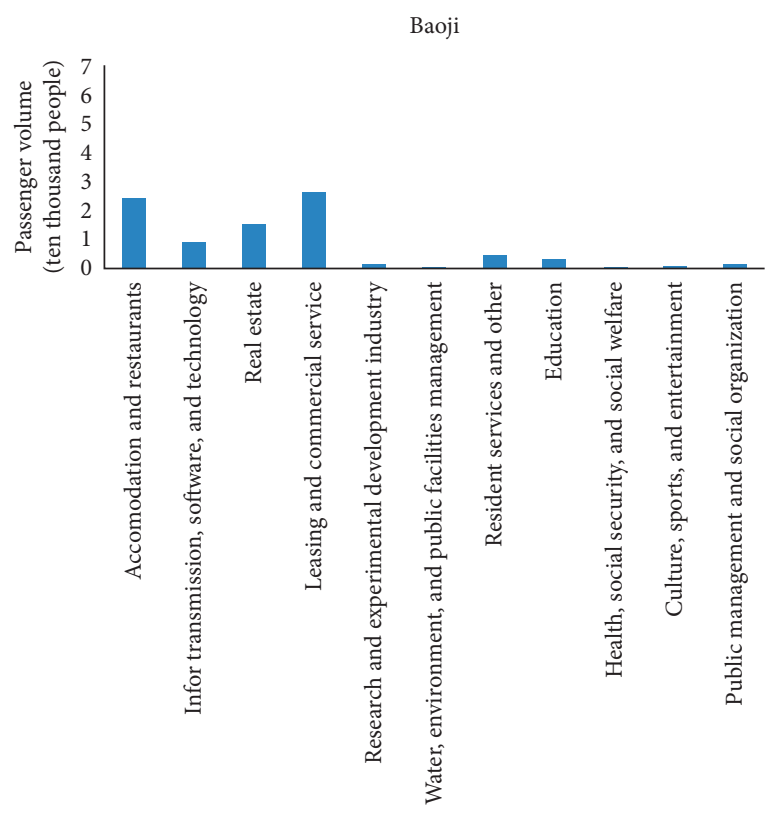

$\mathrm{KY}=13201.208+2645.72 *(1+n)$

[15846.90, 15881.32]

(f)

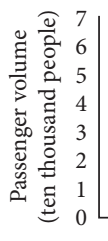

Shangluo

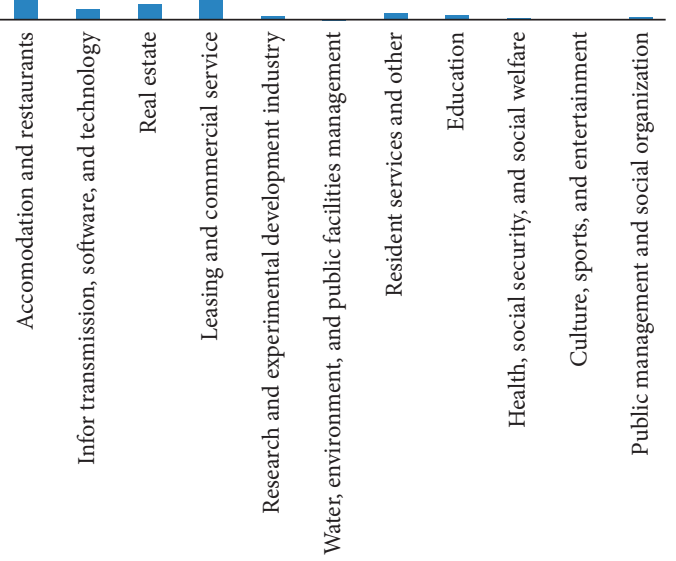

$\mathrm{KY}=5130.205+965.633 *(1+n)$ [6095.83, 6108.39]

(h)

Figure 4: Continued. 


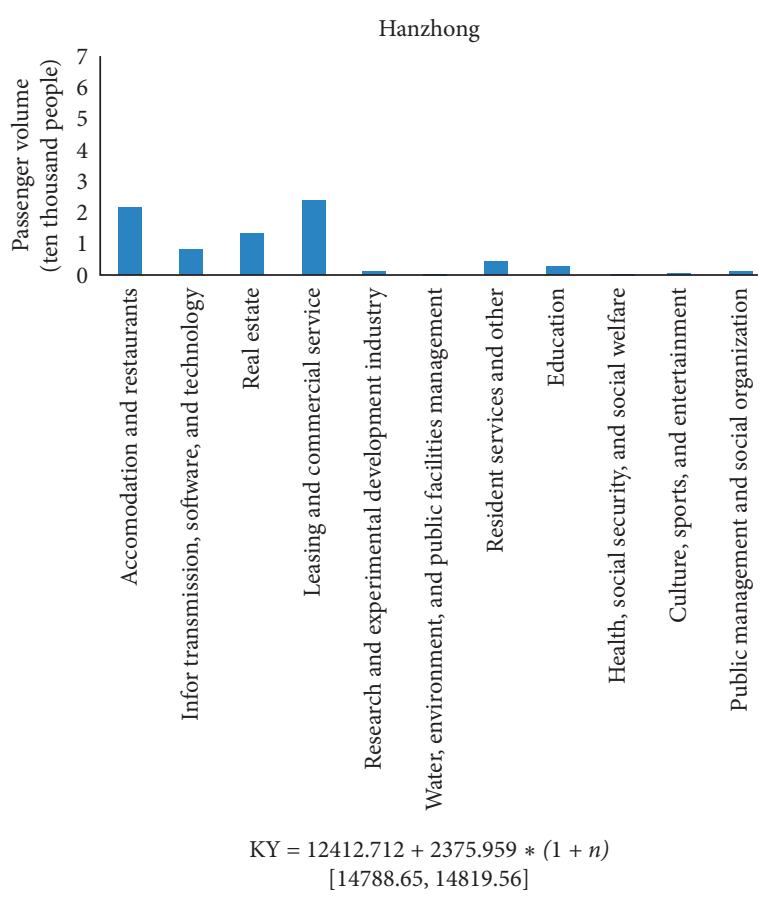

(i)

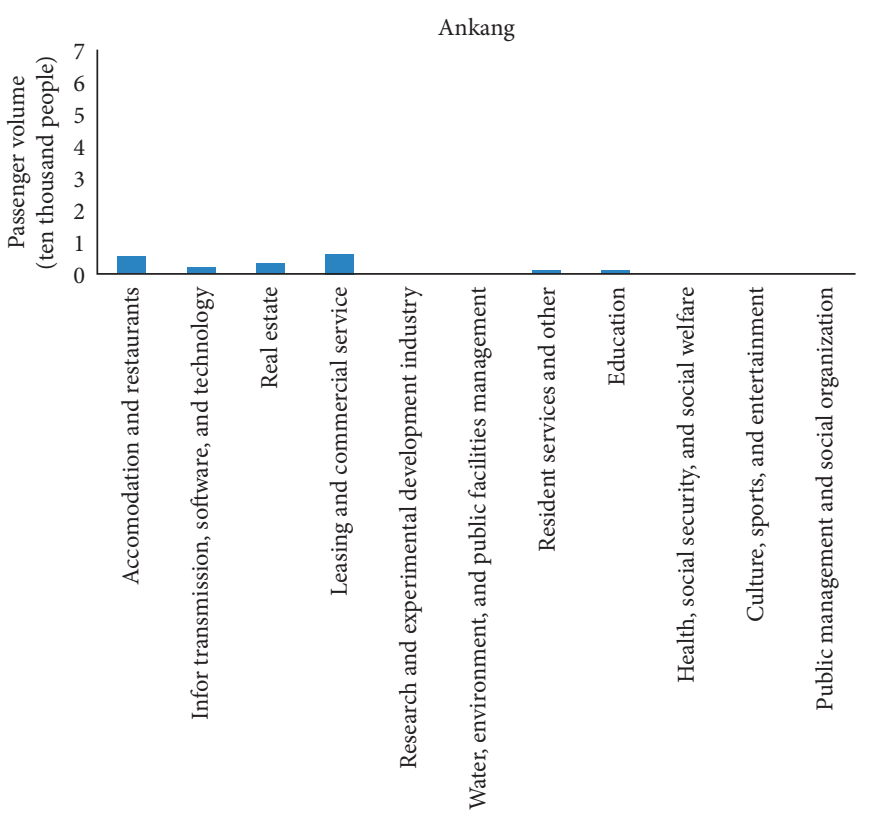

$\mathrm{KY}=9947.269+636.983 *(1+n)$ [10584.24, 10592.53]

(j)

FIgURE 4: Sensitivity of passenger volume and elastic space in 2020 in tens of thousands of people.

By using the same analysis, the passenger volume in the ten cities can be obtained. The passenger volume is strongly influenced by the financial industry. Since there is a large difference in the influences of the financial industry and other industries on the passenger volume, the influence of the financial industry is omitted in order to provide a clearer representation of the influences of the other industries on the passenger volume in cities. In Figure 4, the functions are given for the development speed increased by $1 \%$, and they represent the maximum passenger volume in the cities, while the provided ranges correspond to the passenger volume in 2020 at $n$ of $1.3 \%$.

The influence of the Silk Road Economic Belt on each prefecture-level city is shown in in Figure 4, and the contribution level of each industry can also be clearly known.

The traffic management department of each city can make the construction plan in the next year based on the predicted passenger volume so as to avoid the investment waste or shortage to meet the travel demand.

\section{Conclusion}

Passenger volume prediction is a theoretical foundation for the construction of transportation infrastructure in a region. This study presents the results of passenger volume prediction in a region when the direct and indirect impacts of industrial investment on transportation are considered. Compared to variables like GDP and gross output, the correlation between transportation consumption and passenger volume is the highest. Also, the cities and province's passenger volumes are predicted considering the industry inducement, which can provide an accurate and reliable reference to the planning and construction of Shaanxi Province transportation in the future. The sensitivity analysis is used to analyze the sensitivity of the investment uncertainty of the third industry to the passenger volume in Shaanxi Province. Taking into account the positive impacts of the industries on the passenger volume, the linear relationship between the $1 \%$ increase in the development speed and the passenger volume of the cities and province is obtained; meanwhile, the elastic ranges of the passenger volume in different cities are presented. The proposed model can be used by the transport planners to determine traffic construction capacity and investments in the future, which avoids the insufficient traffic capacity or unnecessary investment. In the future, the predictive accuracy of induced passenger value calculated by the relationships between induced passenger volume, total volume, and trend volume obtained in this paper still needs further analysis and research. Attraction degree, accessibility, and industry complementarity degree can be added to the proposed prediction model to further predict and determine the induced passenger volume in prefecture-level cities. Furthermore, the influence of other policies and special emergency situation will be the next research focus.

\section{Data Availability}

The data used to support the findings of this study are available from the corresponding author upon request.

\section{Conflicts of Interest}

The authors declare that they have no conflicts of interest. 


\section{Acknowledgments}

This research was funded by the Fundamental Research Funds for the Science and Technology Construction Project of Xi'an, Shanxi Province (grant nos. SZJJ2019-22).

\section{References}

[1] L. Chen and R. G. Ma, "Prediction model of passenger transport volume in metropolitan region based on support vector machine," Journal of Traffic and Transportation Engineering, vol. 10, no. 6, pp. 75-81, 2010.

[2] B. Oztaysi, S. Yanik, and C. Kahraman, "Forecasting passenger volumes in transit systems using support vector machines," The Case of Ist, vol. 25, no. 2-3, pp. 215-235, 2015.

[3] P. Wang and C. X. Wu, "Research on subway passenger flow combination prediction model based on RBF neural networks and LSSVM," in Proceedings of the 28th Chinese Control and Decision Conference", pp. 6064-6068, Yinchuan, China, May 2016.

[4] X. Y. Lv and Y. L. Liu, "Forecasting method for total railway passenger flow," Railway Computer Application, vol. 25, no. 2, pp. 1-2, 2016.

[5] M. W. Li, H. G. Kang, and P. F. Zhou, "Urban passenger prediction based on hybrid algorithm of new chaos accelerating genetic algorithm and PPPR model," Systems Engineering-Theory \& Practice, vol. 32, no. 4, pp. 903-910, 2012.

[6] JB. Yuan and X. Li, "Study on highway passenger volume forecast by the method of the GM (1,3)-Markov chain model," Journal of Transportation Engineering, vol. 27, no. 4, pp. 6872, 2001

[7] W. Wu, Z. Fu, and X. Wang, "Passenger volume forecast method for transport corridor," Journal of Railway Science and Engineering, vol. 9, no. 5, pp. 96-102, 2012.

[8] D. K. Yang, "An empirical study on the relationship between the investment on fixed assets and economy growth of China," Thesis, Dongbei University of Finance and Economics, Dalian, China, 2012.

[9] X. H. Li, Q. M. Tan, and A. W. Zhao, “China's passenger traffic forecast based on factor Analysis and logistic model," Journal of System and Management Sciences, vol. 23, no. 8, pp. 444450, 2019.

[10] GS. Mi, L. Liang, and R. X. Yang, "Application of the grey mutation particle swarm algorithm in urban public transport passenger volume prediction," Computing in Science \& Engineering, vol. 37, no. 1, pp. 104-110, 2015.

[11] Y. Xiao, Y. Cheng, and Y. J. Fang, "Research on cloud computing and its application in big data processing of railway passenger flow," in Proceedings of the International "Conference on Applied Engineering and Management", vol. 11-14, pp. 325-330, Beijing, China, September 2015.

[12] N. Glisovic and M. Milenkovic, "A hybrid model for forecasting the volume of passenger flows on Serbian railways," Operational Research, vol. 16, no. 2, pp. 271-285, 2016.

[13] Z. Jing and X. Yin, "Neural network-based prediction model for passenger flow in a large passenger station: an exploratory study," IEEE Access, vol. 8, p. 36876, 2020.

[14] B. Du, H. Peng, S. Wang et al., "Deep irregular convolutional residual LSTM for urban traffic passenger flows prediction," IEEE Transactions on Intelligent Transportation Systems, vol. 21, no. 3, pp. 972-985, 2020.

[15] K. Zhang, Z. Liu, and L. Zheng, "Short-term prediction of passenger demand in multi-zone level: temporal convolutional neural network with multi-task learning," IEEE
Transactions on Intelligent Transportation Systems, vol. 21, no. 4, p. 1480, 2020.

[16] H. W. Zhai and L. C. Tian, "A novel hierarchical hybrid model for short-term bus passenger flow forecasting," Journal of Advanced Transportation, vol. 2020, Article ID 7917353, 2020.

[17] Y. Zhao, Z. Ma, Y. Yang, W. Jiang, and X. Jiang, "Short-term passenger flow prediction with decomposition in urban railway systems," IEEE Access, vol. 8, pp. 107876-107886, 2020.

[18] C. Wang, W. H. Zhang, Z. X. Feng, K. Wang, and Y. H. Gao, "Exploring factors influencing the risky cycling behaviours of young cyclists aged 15-24 years: a questionnaire-based study in China," Risk Analysis, vol. 40, pp. 1-17, 2020.

[19] D. Li, C. Zhang, and J. Cao, "Short-term passenger flow prediction of a passageway in a subway station using time space correlations between multi sites," IEEE Access, vol. 8, pp. 72471-72484, 2020.

[20] X. D. Liu, X. Yang, and F. H. Yan, "Exploring global embodied metal flows in international trade based combination of multiregional input-output analysis and complex network analysis," Resources Policy, vol. 53, Article ID 101661, 2020.

[21] M. Li, Y. Gao, and S. Liu, "China's energy intensity change in 1997-2015: non-vertical adjusted structural decomposition analysis based on input-output tables," Structural Change and Economic Dynamics, vol. 53, pp. 222-236, 2020.

[22] Z. Feng, M. Yang, W. Zhang, Y. Du, and H. Bai, "Effect of longitudinal slope of urban underpass tunnels on drivers' heart rate and speed: a study based on a real vehicle experiment," Tunnelling and Underground Space Technology, vol. 81, pp. 525-533, 2018.

[23] L. Liu, G. Huang, B. Baetz, G. Cheng, S. M. Pittendrigh, and S. Pan, "Input-output modeling analysis with a detailed disaggregation of energy sectors for climate change policymaking: a case study of Saskatchewan, Canada," Renewable Energy, vol. 151, pp. 1307-1317, 2020.

[24] Y. Long, Y. Yoshida, Q. Liu, H. Zhang, S. Wang, and K. Fang, "Comparison of city-level carbon footprint evaluation by applying single- and multi-regional input-output tables," Journal of Environmental Management, vol. 260, Article ID 110108, 2020.

[25] Y. B. Wang, "The correlation between GDP and different transport modes turnover based on grey correlation analysis," in Proceedings of the 2019 4th International Seminar on Computer Technology, Mechanical and Electrical Engineering (ISCME 2019), vol. 1486, Chengdu, China, December 2020.

[26] Q. Wang and L. T. Ren, "Analysis of correlation between shandong's transport and GDP," IEEE International Conference on Automation and Logistics. Shenyang, Peoples $R$ China, vol. 1-2, pp. 1392-1395, 2020.

[27] Z. Feng, J. Zhan, C. Wang, C. Ma, and Z. Huang, "The association between musculoskeletal disorders and driver behaviors among professional drivers in China," International Journal of Occupational Safety and Ergonomics, vol. 26, no. 3, pp. 551-561, 2020. 